\title{
Dexmedetomidine and sufentanil combination versus sufentanil alone for postoperative intravenous patient- controlled analgesia: a systematic review and meta-analysis of randomized controlled trials
}

\author{
Miaomiao Feng, Xuhui Chen, Tongtong Liu, Chuanhan Zhang, Li Wan and Wenlong Yao*
}

\begin{abstract}
Background: Previous studies have demonstrated that dexmedetomidine improves the quality of postoperative analgesia. In the present study, we performed a meta-analysis of randomized controlled trials to quantify the effect of dexmedetomidine as an adjuvant to sufentanil for postoperative patient-controlled analgesia (PCA).

Methods: PubMed, Embase, the Cochrane Library, and Web of Science were systematically searched for randomized controlled trials in which dexmedetomidine was used as an adjuvant for PCA with sufentanil. In the retrieved studies, we quantitatively analyzed pain intensity, sufentanil consumption, and drug-related side effects.

Results: Nine studies with 907 patients were included in this meta-analysis. Compared with sufentanil alone, dexmedetomidine-sufentanil for postoperative intravenous PCA reduced pain intensity at $24 \mathrm{~h}$ (mean difference (MD) $=-0.70$ points; $95 \%$ confidence interval $(C \mathrm{Cl}):-1.01,-0.39 ; P<0.00001)$ and $48 \mathrm{~h}$ postoperatively $(\mathrm{MD}=-0.61$ points; $95 \%$ $\mathrm{Cl}:-1.00,-0.22 ; P=0.002)$. Moreover, dexmedetomidine-sufentanil reduced sufentanil consumption during the first $24 \mathrm{~h}(\mathrm{MD}=-13.77 \mu \mathrm{g} ; 95 \% \mathrm{Cl}:-18.56,-8.97 ; \mathrm{P}<0.00001)$ and $48 \mathrm{~h}$ postoperatively $(\mathrm{MD}=-20.81 \mu \mathrm{g} ; 95 \% \mathrm{Cl}:-28.20,-$ $13.42 ; P<0.00001)$. Finally, dexmedetomidine-sufentanil improved patient satisfaction without increasing the incidence of side effects.
\end{abstract}

Conclusions: Dexmedetomidine as an adjuvant to sufentanil for postoperative PCA can reduce postoperative pain score and sufentanil consumption.

Keywords: Dexmedetomidine, Sufentanil, Patient-controlled analgesia

\section{Background}

Postoperative pain is a common complication after surgery. Notably, effective management of postoperative pain is a core aspect of enhanced recovery after surgery, it reduces hospital stay and overall hospital cost, while enhancing recovery and reducing mortality after surgery $[1,2]$. Intravenous patient-controlled analgesia (PCA) is an effective method for management of postoperative pain,

\footnotetext{
* Correspondence: wlyao82@126.com

Department of Anesthesiology, Tongji Hospital, Tongji Medical College,

Huazhong University of Science and Technology, Wuhan 430030, China
}

because variable pharmacokinetic and pharmacodynamic parameters among patients and drugs can benefit from individual titration [3]. Of the variety of drugs available for postoperative acute pain, opioids are regarded as the preferred treatment. However, opioid use can result in numerous side effects, including excessive sedation, nausea, vomiting, pruritus, constipation, and respiratory depression $[4,5]$; therefore, it is important to provide opioidsparing analgesia. Multimodal pain management has been recommended to enhance pain relief and reduce the side effects of postoperative PCA [6]. 
Dexmedetomidine is a highly selective $\alpha-2$ adrenergic agonist that exhibits hypnotic, sedative, analgesic, and anxiolytic properties [7-9]. Importantly, it does not cause respiratory depression $[9,10]$. Dexmedetomidine has been reported to reduce the incidence of postoperative cognitive dysfunction [11] and to improve postoperative sleep quality [12]. A previous meta-analysis [13] suggested that dexmedetomidine could reduce opioid consumption in postoperative PCA. However, many types of opioids were used for postoperative PCA in that analysis, and opioid consumption was calculated by opioid equianalgesic conversion, which could introduce clinical heterogeneity. Sufentanil is a widely used analgesic drug that provides more intense analgesia with extended duration and milder respiratory depression, compared to equivalent doses of fentanyl or morphine [14]. In recent years, there has been a gradual increase in the number of reports involving the use of sufentanil for intravenous PCA. Therefore, we performed a meta-analysis of randomized controlled trials (RCTs) to quantify the effect of dexmedetomidine as an adjuvant for postoperative PCA with sufentanil.

\section{Methods}

This systematic review and meta-analysis was conducted in accordance with the recommendations of the Cochrane Handbook for Systematic Reviews of Interventions [15], and was reported in accordance with the Preferred Reporting Items for Systematic Reviews and Meta-Analyses (PRISMA) guidelines [16].

\section{Search strategy}

PubMed, Embase, the Cochrane Library, and Web of Science were systematically and independently searched by 2 authors of this review, from the date of inception to January 12,2018 . The search strategy combined free text words and controlled vocabulary Medical Subject Heading terms, including "dexmedetomidine", "sufentanil", "sufentanil citrate", "intravenous", and "analgesia"; only English-language publications were included.

\section{Study inclusion and exclusion criterion}

The eligible criteria were as follows: 1) Participants: adult surgical patients receiving postoperative intravenous PCA; 2) Intervention: dexmedetomidinesufentanil for intravenous PCA; 3) Comparison: sufentanil alone for intravenous PCA; 4) Outcomes: at least 1 of the following outcomes-total sufentanil consumption, pain score, sedation score, patient satisfaction, sufentanil-related side effects (e.g., nausea, vomiting, pruritus, or respiratory depression), or dexmedetomidine- related side effects (e.g., hypotension and bradycardia); 5) Study design: only RCTs were included.

Exclusion criteria were as follows: 1) Use of sufentanil combined with drugs other than dexmedetomidine for postoperative PCA; 2) Use of opioids other than sufentanil for postoperative analgesia; 3) Intraoperative use of dexmedetomidine alone, rather than in combination with sufentanil for PCA after surgery; 4) Lack of specific outcomes reported within the trial; 5) Trials reported in retrospective studies, scientific meetings, correspondence, case reports, or review papers.

\section{Data extraction}

The 2 reviewers independently extracted the following data from the included studies: first author's name; publication year; country; number of patients in each group; type of surgery and anesthesia; and doses of dexmedetomidine and sufentanil in postoperative intravenous PCA. Primary outcomes were: 1) Pain intensity at 24 and $48 \mathrm{~h}$ postoperatively; and 2) Total sufentanil consumption during the first 24 and $48 \mathrm{~h}$ postoperatively. Secondary outcomes were: 1 ) Sedation score at $1 \mathrm{~h}$ postoperatively; 2) Incidences of nausea, vomiting, pruritus, and respiratory depression; 3 ) Number of patients satisfied with intravenous PCA; and 4) Incidences of hypotension and bradycardia. Authors were contacted to obtain additional information, if necessary. Regarding data extraction, any disputes were resolved by discussion with a third reviewer.

\section{Quality assessment}

The 2 authors who performed searching and data extraction then independently read all included studies and evaluated the quality with the Cochrane risk of bias tool [17]. The following 7 items were assessed: random sequence generation (selection bias), allocation concealment (selection bias), blinding of participants and personnel (performance bias), blinding of outcome assessment (detection bias), incomplete outcome data (attrition bias), selective reporting (reporting bias), and other potential biases [17]. Each item was graded as "low risk of bias", "unclear risk of bias", or "high risk of bias". If there was a dispute involving quality assessment, a consensus was reached by discussion with the third reviewer.

\section{Quality of evidence assessment}

The grading of recommendations, assessment, development, and evaluation (GRADE) methodology [18] was used to evaluate the quality of evidence with 4 levels (high, moderate, low, and very low). Assessment items included the risk of bias, inconsistency, indirectness, imprecision, and publication bias. GRADE Pro software (GRADEpro, version 3.6) was used to perform assessments for all outcomes. 


\section{Statistical analysis}

Quantitative analysis was performed using Review Manager 5.3 (The Nordic Cochrane Centre for The Cochrane Collaboration, Copenhagen, Denmark). Pain intensity was assessed using a visual analogue scale (VAS) (0 to 10) or a numerical rating scale (NRS) (0 to 10; 0 indicated "no pain" and 10 indicated the "the worst imaginable pain"). NRS scores (0 to 10) were converted to VAS scores ( 0 to 10) [19]. For continuous data, when studies used median and interquartile range, these data were converted to mean and standard deviation, following an established protocol [20]. For dichotomous data, we calculated the risk ratio (RR) and $95 \%$ confidence interval $(\mathrm{CI})$ by the Mantel-Haenszel method. For continuous data, when measuring methods were different, the standardized mean difference (SMD) with 95\% CI was calculated; otherwise, the mean difference (MD) with 95\% CI was calculated. Statistical heterogeneity was assessed by using the $\mathrm{Q}$ and $\mathrm{I}^{2}$ statistics. $P>0.1$ and $\mathrm{I}^{2}<50 \%$ indicated a low level of heterogeneity among studies; for these, a fixed effects model was used. $P<0.1$ and $\mathrm{I}^{2}>50 \%$ indicated a high level of heterogeneity among studies; for these, a random effects model was used. Due to the limited number $(<10)$ of included studies, publication bias was not evaluated. Sensitivity analysis was performed by excluding each respective study from the pooled results to identify the source of heterogeneity [21] and assess the robustness of the results [22].

\section{Results}

\section{Study selection and characteristics of studies}

A flow diagram of the literature search and evaluation is shown in Fig. 1. A total of 313 records were identified during the initial search (PubMed $=60$, Embase $=92, \mathrm{Web}$ of Science $=94$, and Cochrane Library $=67$ ). Ninety-seven records were excluded due to duplication; 205 were excluded because they did not meet the inclusion criteria upon screening of their titles and abstracts. The remaining 11 publications were screened by reading the full text. One article [23] was excluded because dexmedetomidine for intraoperative anesthesia, rather than for postoperative PCA. One article [24] was excluded because only the abstract was provided in English; another article was excluded because it described an ongoingstudy and only provided a summary. Finally, 9 RCTs [25-33] were included in this meta-analysis.

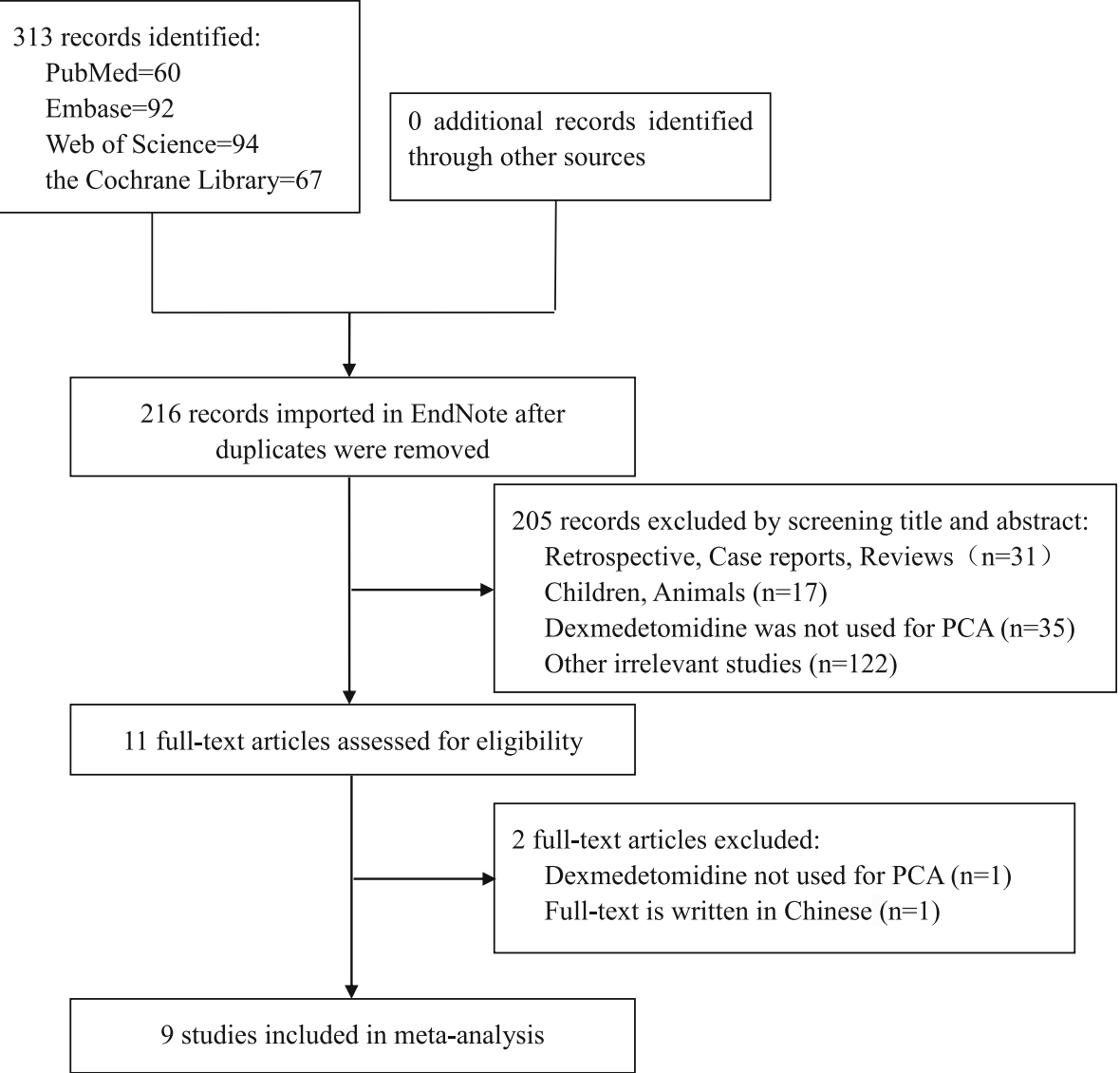

Fig. 1 Study flow chart 
All eligible studies were published during the period from 2014 to 2018; in total, 907 patients were included in this analysis. The main characteristics of the included trials are shown in Table 1, and the PCA protocols are shown in Table 2.

\section{Risk of Bias assessment}

The details of methodologic quality are shown in Fig. 2 . Two studies $[28,30]$ did not describe the details of random sequence generation. One study [25] showed an unclear risk, whereas the remaining 8 studies were judged to be low-risk with respect to blinding of participants and personnel. Two studies [29, 31] solely included male patients; thus, these studies had an unclear risk of other bias. Three studies [27, 29, 33] provided detailed descriptions of the methods of allocation concealment. All studies had low risks of bias due to blinding of outcome assessment, incomplete outcome data, and selective reporting.

\section{Results of meta-analysis}

\section{VAS score at $24 \mathrm{~h}$ postoperatively}

Nine studies reported pain intensity at $24 \mathrm{~h}$ postoperatively. $\mathrm{I}^{2}$ was $83 \%$, which indicated high heterogeneity among the included studies. The pooled results indicated that patients receiving postoperative PCA with dexmedetomidine-sufentanil combination exhibited a significant reduction in pain intensity at $24 \mathrm{~h}$ postoperatively, compared with patients receiving sufentanil alone $(\mathrm{MD}=-0.70$ points; $95 \% \mathrm{CI}:-1.01,-0.39 ; P<$ 0.00001, Fig. 3a).

\section{VAS score at $48 \mathrm{~h}$ postoperatively}

Seven studies reported pain intensity at $48 \mathrm{~h}$ postoperatively. $\mathrm{I}^{2}$ was $88 \%$, which indicated high heterogeneity among the included studies. Compared with patients receiving sufentanil alone for postoperative PCA, patients receiving dexmedetomidine-sufentanil combination for postoperative PCA exhibited a significant reduction in

Table 1 Characteristics of Included Trials

\begin{tabular}{|c|c|c|c|c|c|c|}
\hline Trials (year) & Country & Group & Surgery & Anesthesia & Intraoperative Analgesia & Outcomes \\
\hline $\begin{array}{l}\text { Chen } 2017 \\
\text { [25] }\end{array}$ & China & $\begin{array}{l}\text { Control }(n= \\
29) \\
\operatorname{DEX}(n=30)\end{array}$ & $\begin{array}{l}\text { abdominal } \\
\text { hysterectomy }\end{array}$ & general anesthesia & remifentanil & $1,2,3,4,5$ \\
\hline Gao 2018 [26] & China & $\begin{array}{l}\text { Control }(n= \\
101) \\
\operatorname{DEX}(n=102)\end{array}$ & abdominal operation & general anesthesia & Not specified & $1,2,3,6,7,8,9,10$ \\
\hline Nie 2014 [27] & China & $\begin{array}{l}\text { Control }(n= \\
38) \\
\operatorname{DEX}(n=38)\end{array}$ & caesarean section & spinal anesthesia & $\begin{array}{l}\text { bupivacaine } \\
\text { bupivacaine +DEX }\end{array}$ & $1,3,6,8,9,10,11$ \\
\hline $\begin{array}{l}\text { Dong } 2017 \\
\text { [28] }\end{array}$ & China & $\begin{array}{l}\text { Control }(n= \\
30) \\
\operatorname{DEX}(n=30)\end{array}$ & $\begin{array}{l}\text { thoracotomy } \\
\text { operation }\end{array}$ & general anesthesia & sufentanil & $\begin{array}{l}1,2,3,4,6,7,8,9,10 \\
11\end{array}$ \\
\hline Qin 2017 [29] & China & $\begin{array}{l}\text { Control }(n= \\
29) \\
\operatorname{DEX}(n=29)\end{array}$ & partial laryngectomy & general anesthesia & sufentanil+DEX & $1,3,6,7,8,9,10,11$ \\
\hline Lu 2017 [30] & China & $\begin{array}{l}\text { Control }(n= \\
76) \\
\operatorname{DEX}(n=75)\end{array}$ & shoulder arthroscopy & $\begin{array}{l}\text { general anesthesia+ brachial plexus } \\
\text { block }\end{array}$ & $\begin{array}{l}\text { DEX+ ropivacaine+ } \\
\text { remifentanil }\end{array}$ & $1,2,3,5,6,7,9,11$ \\
\hline Ren 2015 [31] & China & $\begin{array}{l}\text { Control }(n= \\
41) \\
\text { DEX1 }(n=41) \\
\text { DEX } 2(n= \\
43)\end{array}$ & thoracic surgery & general anesthesia & DEX + sufentanil & $1,2,3,4,5,6,7,11$ \\
\hline Ren 2015 [32] & China & $\begin{array}{l}\text { Control }(n= \\
27) \\
\operatorname{DEX} 1(n=28) \\
\operatorname{DEX} 2(n= \\
27)\end{array}$ & $\begin{array}{l}\text { abdominal } \\
\text { hysterectomy }\end{array}$ & general anesthesia & $\begin{array}{l}\text { sufentanil } \\
\text { DEX + sufentanil } \\
\text { DEX + sufentanil }\end{array}$ & $1,2,3,4,5,6,7,9,11$ \\
\hline Xin 2017 [33] & China & $\begin{array}{l}\text { Control }(n= \\
47) \\
\operatorname{DEX}(n=46)\end{array}$ & laparotomy surgery & general anesthesia & remifentanil & $1,2,6,8,9,10,11$ \\
\hline
\end{tabular}

1. pain scores at $24 \mathrm{~h}$ postoperatively; 2 . pain scores at $48 \mathrm{~h}$ postoperatively; 3 . sufentanil consumption during the first $24 \mathrm{~h}$ postoperatively; 4 . sufentanil consumption during the first $48 \mathrm{~h}$ postoperatively; 5 . sedation score at $1 \mathrm{~h}$ postoperatively; 6 . the incidence of PONV; 7 . the incidence of pruritus; 8 . patient satisfaction; 9 . the incidence of bradycardia; 10 . the incidence of hypotension; 11 . the incidenceof respiratory depression

$D E X=$ dexmedetomidine, $P O N V=$ postoperative nausea and vomiting 
Table 2 PCA Protocols

\begin{tabular}{|c|c|c|c|c|c|c|}
\hline \multirow[t]{2}{*}{ Trials } & \multirow[t]{2}{*}{ Group } & \multicolumn{2}{|c|}{ PCA Background Infusion } & \multicolumn{2}{|l|}{ Bolus Dose } & \multirow[t]{2}{*}{ Lockout Interva } \\
\hline & & sufentanil & DEX & sufentanil & DEX & \\
\hline \multirow[t]{2}{*}{ Chen 2017 [25] } & Control & $0.02 \mu \mathrm{g} \mathrm{kg}^{-1} \mathrm{~h}^{-1}$ & - & $0.02 \mu \mathrm{g} / \mathrm{kg}$ & - & $10 \mathrm{~min}$ \\
\hline & DEX + sufentanil & $0.02 \mu \mathrm{kg}^{-1} \mathrm{~h}^{-1}$ & $0.05 \mu \mathrm{gg}^{-1} \mathrm{~h}^{-1}$ & $0.02 \mu \mathrm{g} / \mathrm{kg}$ & $0.05 \mu \mathrm{g} / \mathrm{kg}$ & $10 \mathrm{~min}$ \\
\hline \multirow[t]{2}{*}{ Gao 2018 [26] } & Control & $2 \mu \mathrm{g} / \mathrm{h}$ & - & $2 \mu \mathrm{g}$ & - & $5 \mathrm{~min}$ \\
\hline & DEX + sufentanil & $2 \mu \mathrm{g} / \mathrm{h}$ & $4 \mu \mathrm{g} / \mathrm{h}$ & $2 \mu \mathrm{g}$ & $4 \mu \mathrm{g}$ & $5 \min$ \\
\hline \multirow[t]{2}{*}{ Nie 2014 [27] } & Control & $0.015 \mu \mathrm{g} \mathrm{kg}^{-1} \mathrm{~h}^{-1}$ & - & $0.023 \mu \mathrm{g} / \mathrm{kg}$ & - & $8 \mathrm{~min}$ \\
\hline & DEX + sufentanil & $0.015 \mu \mathrm{g} \mathrm{kg}^{-1} \mathrm{~h}^{-1}$ & $0.045 \mu \mathrm{g} \mathrm{kg}^{-1} \mathrm{~h}^{-1}$ & $0.023 \mu \mathrm{g} / \mathrm{kg}$ & $0.07 \mu \mathrm{g} / \mathrm{kg}$ & $8 \min$ \\
\hline \multirow[t]{2}{*}{ Dong 2017 [28] } & Control & $0.048 \mu \mathrm{g} \cdot \mathrm{kg}^{-1} \cdot \mathrm{h}^{-1}$ & - & $0.024 \mu \mathrm{g} / \mathrm{kg}$ & - & $10 \mathrm{~min}$ \\
\hline & DEX + sufentanil & $0.048 \mu \mathrm{g} \cdot \mathrm{kg}^{-1} \cdot \mathrm{h}^{-1}$ & $0.064 \mu \mathrm{g} \cdot \mathrm{kg}^{-1} \cdot \mathrm{h}^{-1}$ & $0.024 \mu \mathrm{g} / \mathrm{kg}$ & $0.032 \mu \mathrm{g} / \mathrm{kg}$ & $10 \mathrm{~min}$ \\
\hline \multirow[t]{2}{*}{ Qin 2017 [29] } & Control & $1.5 \mu \mathrm{g} / \mathrm{h}$ & - & $1.5 \mu \mathrm{g}$ & - & $10 \mathrm{~min}$ \\
\hline & DEX + sufentanil & $1.5 \mu \mathrm{g} / \mathrm{h}$ & $6 \mu \mathrm{g} / \mathrm{h}$ & $1.5 \mu \mathrm{g}$ & $6 \mu \mathrm{g}$ & $10 \mathrm{~min}$ \\
\hline \multirow[t]{2}{*}{ Lu 2017 [30] } & Control & $0.04 \mu \mathrm{gg}^{-1} \mathrm{~h}^{-1}$ & - & $0.03 \mu \mathrm{g} / \mathrm{kg}$ & - & $5 \mathrm{~min}$ \\
\hline & DEX + sufentanil & $0.04 \mu \mathrm{kg}^{-1} \mathrm{~h}^{-1}$ & $0.06 \mu \mathrm{kg}^{-1} \mathrm{~h}^{-1}$ & $0.03 \mu \mathrm{g} / \mathrm{kg}$ & $0.045 \mu \mathrm{g} / \mathrm{kg}$ & $5 \mathrm{~min}$ \\
\hline \multirow[t]{3}{*}{ Ren 2015 [31] } & Control & $0.02 \mu \mathrm{gg}^{-1} \mathrm{~h}^{-1}$ & - & $0.02 \mu \mathrm{g} / \mathrm{kg}$ & - & $5 \min$ \\
\hline & DEX + sufentanil 1 & $0.02 \mu \mathrm{gg}^{-1} \mathrm{~h}^{-1}$ & $0.02 \mu \mathrm{g} \mathrm{kg}^{-1} \mathrm{~h}^{-1}$ & $0.02 \mu \mathrm{g} / \mathrm{kg}$ & $0.02 \mu \mathrm{g} / \mathrm{kg}$ & $5 \mathrm{~min}$ \\
\hline & DEX + sufentanil 2 & $0.02 \mu \mathrm{gg}^{-1} \mathrm{~h}^{-1}$ & $0.04 \mu \mathrm{gg}^{-1} \mathrm{~h}^{-1}$ & $0.02 \mu \mathrm{g} / \mathrm{kg}$ & $0.04 \mu \mathrm{g} / \mathrm{kg}$ & $5 \min$ \\
\hline \multirow[t]{3}{*}{ Ren 2015 [32] } & Control & $0.02 \mu \mathrm{kg}^{-1} \mathrm{~h}^{-1}$ & - & $0.02 \mu \mathrm{g} / \mathrm{kg}$ & - & $8 \mathrm{~min}$ \\
\hline & DEX + sufentanil 1 & $0.02 \mu \mathrm{g} \mathrm{kg}^{-1} \mathrm{~h}^{-1}$ & $0.02 \mu \mathrm{g} \mathrm{kg}^{-1} \mathrm{~h}^{-1}$ & $0.02 \mu \mathrm{g} / \mathrm{kg}$ & $0.02 \mu \mathrm{g} / \mathrm{kg}$ & $8 \mathrm{~min}$ \\
\hline & DEX + sufentanil 2 & $0.02 \mu \mathrm{g} \mathrm{kg}^{-1} \mathrm{~h}^{-1}$ & $0.05 \mu \mathrm{kg}^{-1} \mathrm{~h}^{-1}$ & $0.02 \mu \mathrm{g} / \mathrm{kg}$ & $0.05 \mu \mathrm{g} / \mathrm{kg}$ & $8 \mathrm{~min}$ \\
\hline \multirow[t]{2}{*}{ Xin 2017 [33] } & Control & $0.04 \mu \mathrm{kg}^{-1} \mathrm{~h}^{-1}$ & - & $0.01 \mu \mathrm{g} / \mathrm{kg}$ & - & $15 \min$ \\
\hline & DEX + sufentanil & $0.02 \mu \mathrm{gg}^{-1} \mathrm{~h}^{-1}$ & $0.04 \mu \mathrm{kg}^{-1} \mathrm{~h}^{-1}$ & $0.005 \mu \mathrm{g} / \mathrm{kg}$ & $0.01 \mu \mathrm{g} / \mathrm{kg}$ & $15 \min$ \\
\hline
\end{tabular}

$D E X=$ dexmedetomidine

pain scores at $48 \mathrm{~h}$ postoperatively $(\mathrm{MD}=-0.61$ points; 95\% CI: $-1.00,-0.22 ; P=0.002$, Fig. 3b).

\section{Total sufentanil consumption during the first $24 \mathrm{~h}$ postoperatively}

Eight studies reported total sufentanil consumption during the first $24 \mathrm{~h}$ postoperatively. The study by $\mathrm{Lu}$ et al. [30] measured sufentanil consumption in milliliters (ml) with an unclear concentration; other studies measured sufentanil consumption in micrograms $(\mu \mathrm{g})$. After removing the study by $\mathrm{Lu}$ et al., the MD with $95 \% \mathrm{CI}$ was calculated. $\mathrm{I}^{2}$ was $92 \%$, which indicated high heterogeneity among the included studies. The pooled results indicated that patients receiving dexmedetomidine-sufentanil combination for postoperative PCA exhibited a significant reduction in total sufentanil consumption at $24 \mathrm{~h}$ postoperatively, compared with patients receiving sufentanil alone $(\mathrm{MD}=-13.77 \mu \mathrm{g}$; 95\% CI: - 18.56, - 8.97; $P<0.00001$, Fig. 4a).

\section{Total sufentanil consumption during the first $48 \mathrm{~h}$ postoperatively}

Four studies reported the total sufentanil consumption during the first $48 \mathrm{~h}$ postoperatively. $\mathrm{I}^{2}$ was $90 \%$, which indicated high heterogeneity among the included studies.
The pooled results suggested that the combination of dexmedetomidine and sufentanil for PCA significantly reduced sufentanil consumption during the first $48 \mathrm{~h}$ postoperatively, compared with sufentanil alone (MD $=-20.81 \mu \mathrm{g} ;$ 95\% CI: $-28.20,-13.42 ; P<0.00001$, Fig. 4b).

\section{Sedation score at $1 \mathrm{~h}$ postoperatively}

Four studies reported the sedation score at $1 \mathrm{~h}$ postoperatively. $\mathrm{I}^{2}$ was $2 \%$, which indicated low heterogeneity among the included studies. The results indicated that patients receiving postoperative PCA with dexmedetomidine-sufentanil combination exhibited higher sedation scores at $1 \mathrm{~h}$ postoperatively, compared with patients receiving sufentanil alone (SMD $=0.27 ; 95 \%$ CI: $0.07,0.47 ; P=0.008$, Fig. 5). Sensitivity analysis showed no significant differences between the two groups upon removal of the trials of $\mathrm{Lu}$ et al. [30] or Ren et al. [32], which indicated inconsistent results.

\section{Sufentanil-related adverse events}

Eight studies described the incidences of nausea, vomiting, and pruritus. Compared with patients receiving sufentanil 


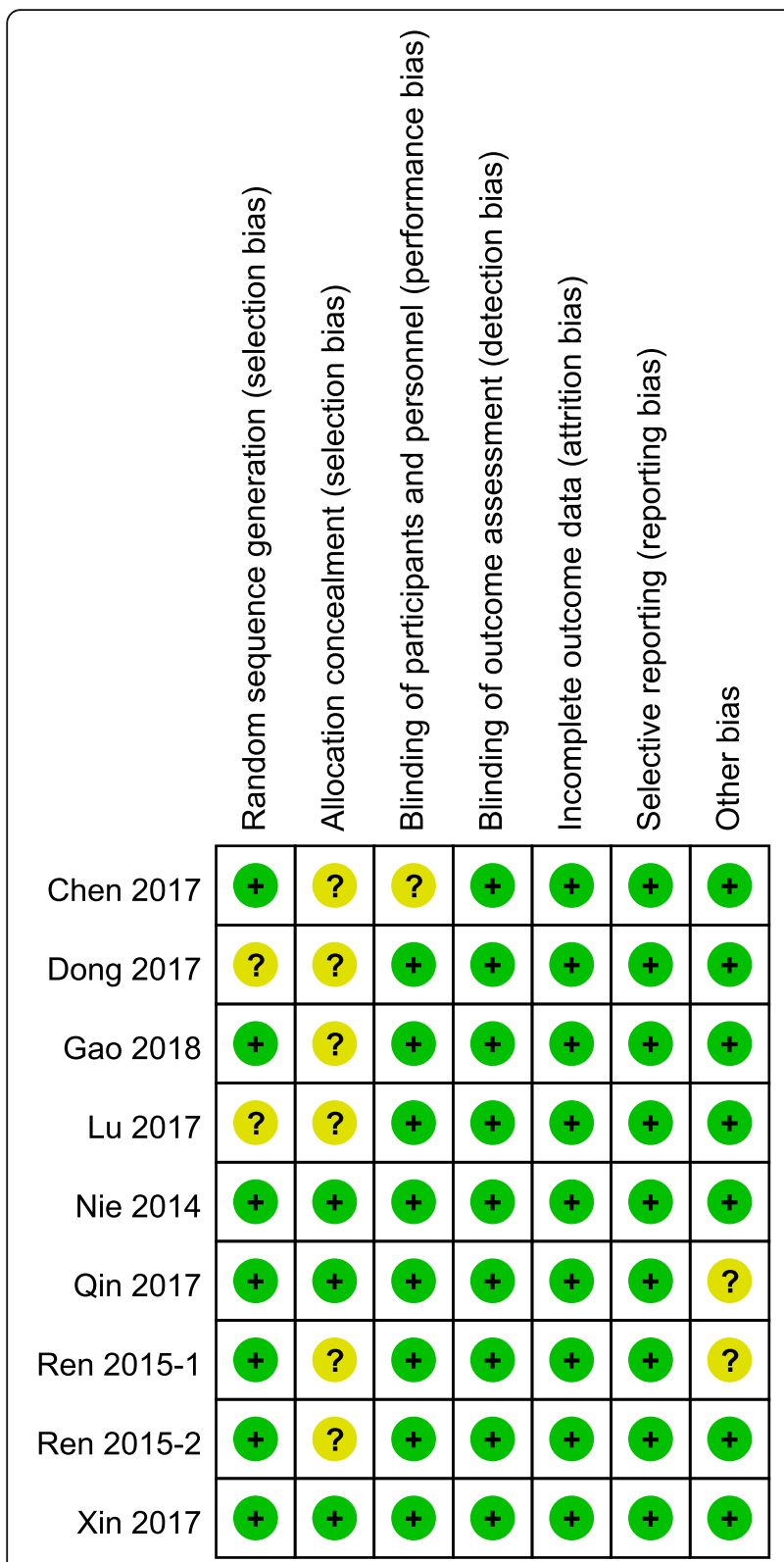

Fig. 2 Risk of bias of the included studies, based on the Cochrane risk of bias tool

alone, there were lower incidences of postoperative nausea $\left(\mathrm{RR}=0.68,95 \%\right.$ CI: 0.53, 0.87; $P=0.002, \mathrm{I}^{2}=3 \%$, Fig. 6a), vomiting ( $R R=0.56,95 \% C I$ : $0.37,0.83 ; P=0.004, \mathrm{I}^{2}=2 \%$, Fig. $6 \mathrm{~b})$, and pruritus ( $\mathrm{RR}=0.54,95 \% \mathrm{CI}: 0.34,0.83 ; P=$ $\left.0.006, \mathrm{I}^{2}=0 \%\right)$ in patients receiving dexmedetomidinesufentanil combination for postoperative PCA. Only 1 study [28] reported the incidence of respiratory depression (respiratory rate $<$ beats per minute, lasting for more than $10 \mathrm{~min}$ ); it found no significant difference between the dexmedetomidine- sufentanil and sufentanil groups.

\section{Patient satisfaction}

Four studies reported the number of patients who were satisfied with intravenous PCA. $\mathrm{I}^{2}$ was $67 \%$, which indicated high heterogeneity in the included studies. Patients receiving postoperative intravenous PCA with dexmedetomidinesufentanil combination exhibited higher satisfaction than those receiving sufentanil alone $(\mathrm{RR}=1.41,95 \% \mathrm{CI}: 1.12$, 1.77; $P=0.003$, Fig. 7).

\section{Other outcomes}

No significant differences were observed in the incidences of hypotension ( $\mathrm{RR}=1.39,95 \% \mathrm{CI}: 0.28,6.93 ; P$ $\left.=0.69, \mathrm{I}^{2}=30 \%\right)$ or bradycardia $(\mathrm{RR}=1.83,95 \% \mathrm{CI}: 0.81$, 4.15; $P=0.15, \mathrm{I}^{2}=0 \%$ ) between the 2 groups.

\section{GRADE assessment}

The qualities of evidence according to the GRADE approach are shown in Table 3. The GRADE level of evidence was very low for total sufentanil consumption during the first 24 and $48 \mathrm{~h}$ postoperatively, as well as for VAS scores at 24 and $48 \mathrm{~h}$ postoperatively. The GRADE level of evidence was low for sedation score at $1 \mathrm{~h}$ postoperatively, whereas it was moderate for patient satisfaction. The GRADE levels of evidence were high for the incidences of postoperative nausea, vomiting, pruritus, hypotension, and bradycardia.

\section{Discussion}

In this meta-analysis, we quantified the effect of dexmedetomidine as an adjuvant to sufentanil for PCA and found that dexmedetomidine improved postoperative pain intensity and reduced total sufentanil consumption. Furthermore, sufentanil-related side effects (e.g., postoperative nausea, vomiting, and pruritus) were reduced in the dexmedetomidine-sufentanil group; the incidences of dexmedetomidine-associated side effects (e.g., bradycardia and hypotension) did not increase.

In the past few decades, intravenous PCA has been commonly used for postoperative analgesia [34, 35]. Sufentanil is commonly used for the treatment of moderate to severe postoperative pain; however, the risk of adverse effects limits its use as a single method to manage postoperative pain [36-38]. Dexmedetomidine achieves ananalgesic effect by activation of $\alpha-2$ adrenoceptors, thereby acting in a manner that differs from sufentanil; notably, combination of these drugs produces a synergistic analgesic effect without increasing the risk of respiratory depression [39].

Sufentanil-related complications were significantly reduced, while patient satisfaction was improved in the dexmedetomidine-sufentanil group, compared to the sufentanil group. These changes may be explained as follows: 1) Patients receiving dexmedetomidine-sufentanil combination for PCA used lower doses of sufentanil; and 


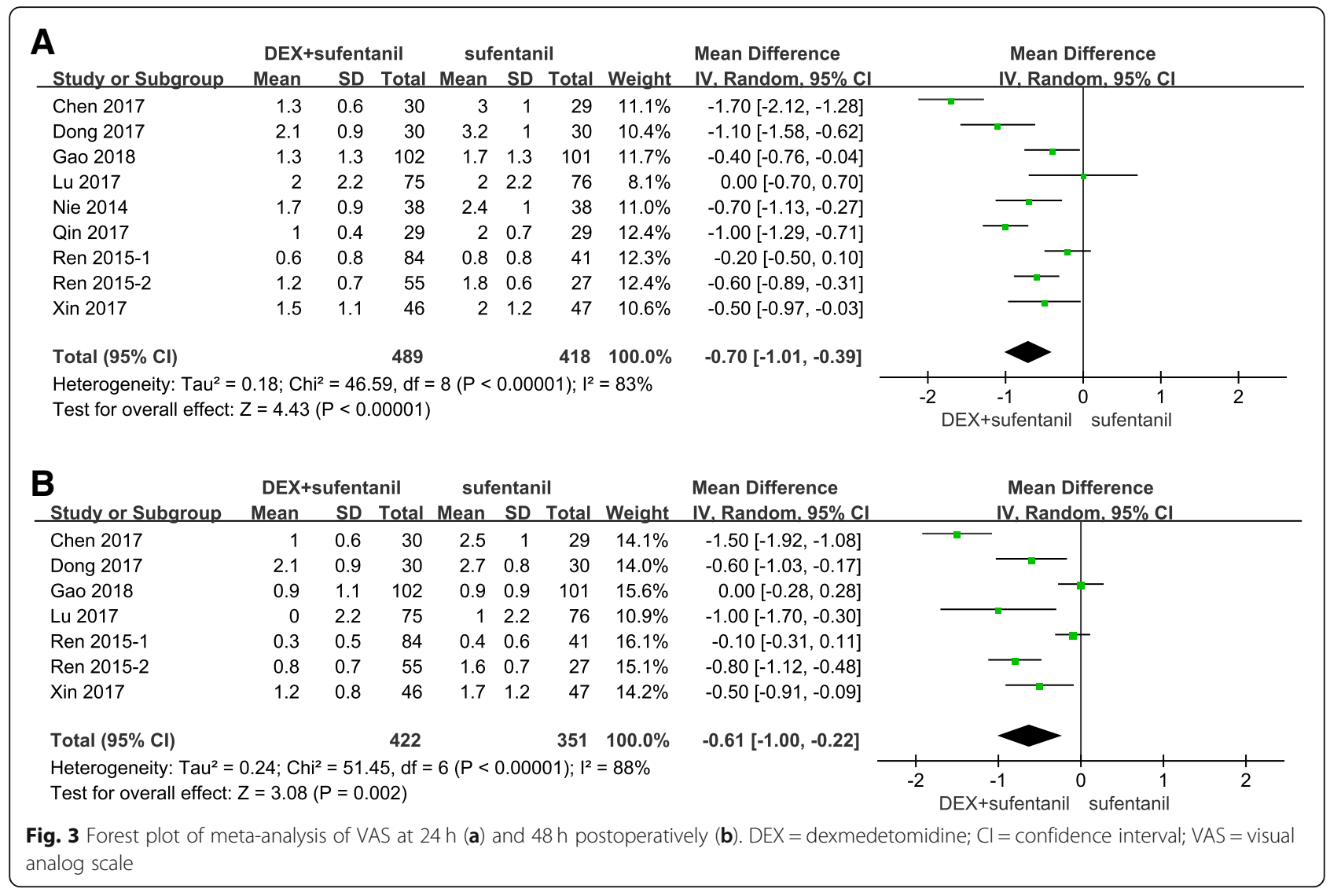

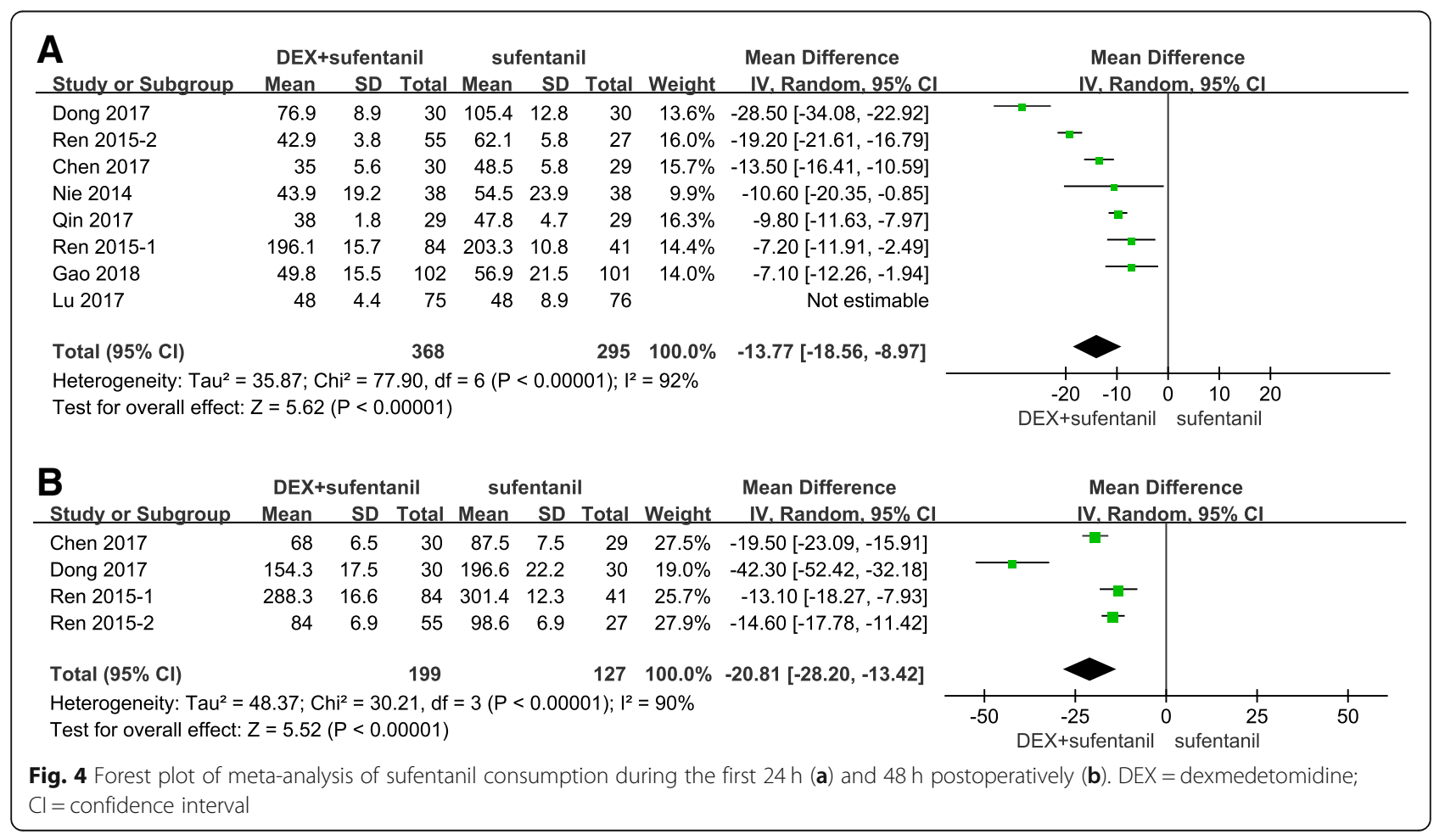




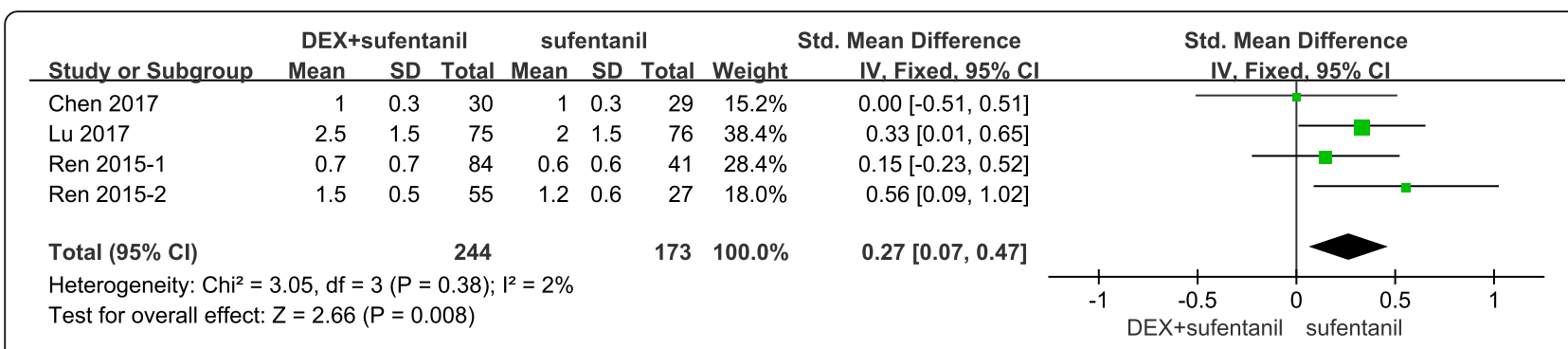

Fig. 5 Forest plot of meta-analysis of sedation score at $1 \mathrm{~h}$ postoperatively. $\mathrm{DEX}=$ dexmedetomidine; $\mathrm{Cl}=$ confidence interval

2) Dexmedetomidine can decrease noradrenergic activity by inhibiting presynaptic $\alpha 2$ receptors in the locus coeruleus, or by reducing sympathetic outflow, which may induce postoperative nausea and vomiting [40].

With respect to the safety characteristics involved in the addition of dexmedetomidine to postoperative intravenous PCA, hypotension and bradycardia have been identified as the primary concerns [41]. In particular, for patients with stroke or coronary disease, the hypotensive or bradycardic actions of dexmedetomidine may be harmful. Upon administration of a high dose or rapid intravenous injection, dexmedetomidine produces hypertension by activating $\alpha-2$ adrenoceptors on smooth muscle cells. When administered at clinically recommended concentrations, dexmedetomidine produces dose-dependent hypotension and bradycardia, due to the inhibition of neurotransmission in sympathetic nerves and reduction of sympathetic tone; this effect may also be mediated by the baroreceptor reflex and enhanced vagal activity [9, 10, 42]. In the present study, pooled results demonstrated no significant differences in the incidences of hypotension or bradycardia between the dexmedetomidine-sufentanil and sufentanil group; this might be a result of the small dose of dexmedetomidine used in these studies. Although no statistically significant difference was detected, there remains considerable concern with respect to the potential risks of hypotension and severe bradycardia associated

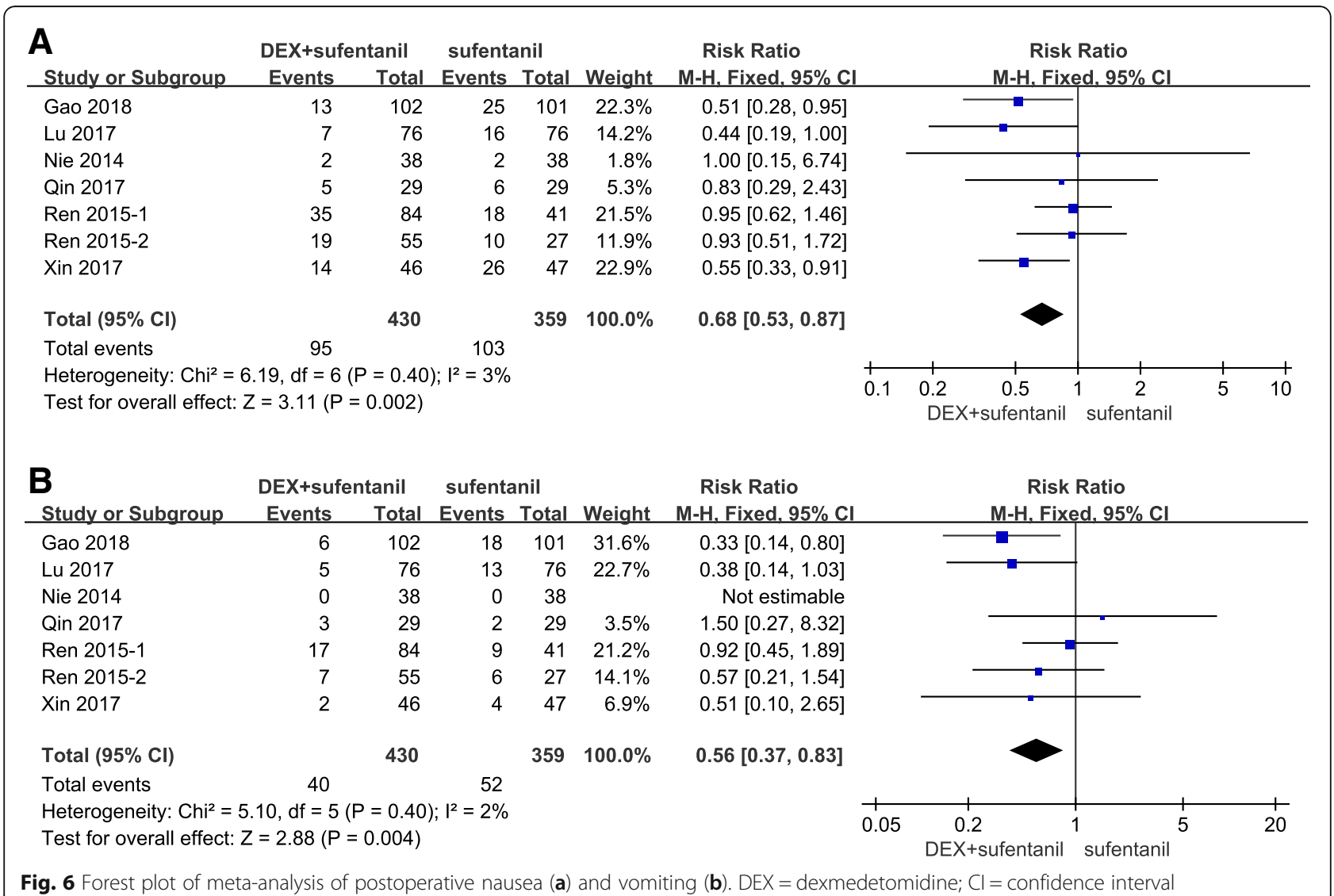




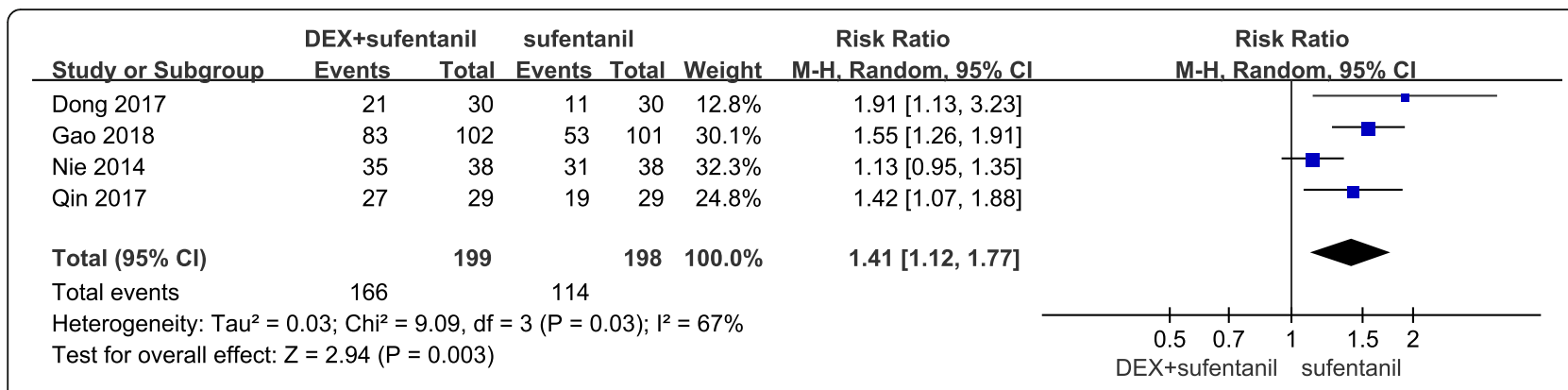

Fig. 7 Forest plot of meta-analysis of patient satisfaction. $\mathrm{DEX}=$ dexmedetomidine; $\mathrm{Cl}=$ confidence interval

with the use of dexmedetomidine. Moreover, dexmedetomidine could inhibit the release of corticosterone in response to adrenocorticotropic hormone stimulation after prolonged use or high dosage [43]. Enomoto et al. [44] reported that long-term dexmedetomidine administration might cause tolerance in infants, but there have been no reports of long-term use of dexmedetomidine for PCA in adults, likely because PCA is typically used for 2-3 days after surgery. Nonetheless, rebound hypertension and tachycardia after abrupt cessation of dexmedetomidine, as well as changes in tolerance and the potential for withdrawal syndrome, remain concerns when using dexmedetomidine.

The pooled results indicated that, regardless of the type of sedation score used, patients receiving postoperative intravenous PCA with dexmedetomidine-sufentanil combination exhibited higher sedation scores at $1 \mathrm{~h}$ postoperatively, compared with patients receiving sufentanil alone. However, interpretation of this result requires caution, because sensitivity analysis showed that there was no

Table 3 The Quality of Evidences

\begin{tabular}{|c|c|c|c|c|}
\hline Outcome & MD/RR (95\%Cl) & $\begin{array}{l}\text { Number of Participants } \\
\text { (studies) }\end{array}$ & $\begin{array}{l}\text { Quality of the } \\
\text { evidence (GRADE) }\end{array}$ & Comments \\
\hline $\begin{array}{l}\text { VAS score at } 24 \mathrm{~h} \\
\text { postoperatively }\end{array}$ & $\begin{array}{l}\mathrm{MD}-0.70[-1.01,- \\
0.39]\end{array}$ & 907(9 studies) & $\begin{array}{l}\oplus 000 \\
\text { Very Low }\end{array}$ & $\begin{array}{l}\mathrm{I}^{2} \text { statistic shows high level of heterogeneity at 83\%, } \\
\text { when studies used median and interquartile range, } \\
\text { we converted these to mean and standard } \\
\text { deviation (SD). We downgraded the quality of evidence } \\
\text { for inconsistency and indirectness. }\end{array}$ \\
\hline $\begin{array}{l}\text { VAS score at } 48 \mathrm{~h} \\
\text { postoperatively }\end{array}$ & $\begin{array}{l}\mathrm{MD}-0.61[-1.00,- \\
0.22]\end{array}$ & 773(7 studies) & $\begin{array}{l}\oplus 000 \\
\text { Very Low }\end{array}$ & $\begin{array}{l}\mathrm{I}^{2} \text { statistic shows high level of heterogeneity at 88\% } \\
\text { and when studies used median and interquartile } \\
\text { range, we converted these to mean and standard } \\
\text { deviation (SD). We downgraded the quality of } \\
\text { evidence for inconsistency, indirectness. }\end{array}$ \\
\hline $\begin{array}{l}\text { Total sufentanil consumption } \\
\text { during the first } 24 \mathrm{~h} \\
\text { postoperatively }\end{array}$ & $\begin{array}{l}\text { MD }-13.77[-18.56 \\
-8.97]\end{array}$ & 663(7 studies) & $\begin{array}{l}\oplus 00 \bigcirc \\
\text { Very Low }\end{array}$ & $\begin{array}{l}\mathrm{I}^{2} \text { statistic shows high level of heterogeneity at } 92 \% \\
\text { and part data were extracted from figures. We } \\
\text { downgraded the quality of evidence for inconsistency, } \\
\text { indirectness. }\end{array}$ \\
\hline $\begin{array}{l}\text { Total sufentanil consumption } \\
\text { during the first } 48 \mathrm{~h} \\
\text { postoperatively }\end{array}$ & $\begin{array}{l}M D-20.81[-28.20,- \\
13.42]\end{array}$ & 326(4 studies) & $\begin{array}{l}\oplus 00 \bigcirc \\
\text { Very Low }\end{array}$ & $\begin{array}{l}\mathrm{I}^{2} \text { statistic shows high level of heterogeneity at } 90 \% \\
\text { and part data were extracted from figures. We } \\
\text { downgraded the quality of evidence for inconsistency, } \\
\text { indirectness. }\end{array}$ \\
\hline $\begin{array}{l}\text { Sedation score at } 1 \mathrm{~h} \\
\text { postoperatively }\end{array}$ & - & 417(4 studies) & $\begin{array}{l}\oplus \oplus \mathrm{OO} \\
\text { LOW }\end{array}$ & $\begin{array}{l}\text { SMD0.27 [0.07, } 0.47] \\
\text { When studies used median and interquartile range, } \\
\text { we converted these to mean and standard deviation } \\
\text { (SD) and part data were extracted from figures. We } \\
\text { downgraded the quality of evidence for indirectness } \\
\text { and inconsistency. }\end{array}$ \\
\hline Postoperative nausea & RR $0.68[0.53,0.87]$ & 789(7 studies) & $\oplus \oplus \oplus \oplus$ High & \\
\hline Postoperative vomiting & RR $0.56[0.37,0.83]$ & 789(7 studies) & $\oplus \oplus \oplus \oplus$ High & \\
\hline Pruritus & RR $0.54[0.34,0.83]$ & 680(6 studies) & $\oplus \oplus \oplus \oplus$ High & \\
\hline Patients' satisfaction & RR $1.41[1.12,1.77]$ & 397(4 studies) & $\begin{array}{l}\oplus \oplus \oplus \bigcirc \\
\text { Moderate }\end{array}$ & $\begin{array}{l}\mathrm{I}^{2} \text { statistic shows heterogeneity at } 67 \% \text {. We } \\
\text { downgraded the quality of evidence for inconsistency. }\end{array}$ \\
\hline Hypotension & $\operatorname{RR} 1.39[0.28,6.93]$ & 490(5 studies) & $\oplus \oplus \oplus \oplus$ High & \\
\hline Bradycardia & RR $1.83[0.81,4.15]$ & 723(7 studies) & $\oplus \oplus \oplus \oplus$ High & \\
\hline
\end{tabular}


significant difference between the 2 groups. Notably, no oversedation events were reported in the included studies. Thus, the clinical significance of the outcome regarding postoperative sedation scores is unclear and further investigation is needed.

Peng et al. [13] found that patients receiving an opioid-dexmedetomidine combination for postoperative PCA experienced significantly greater pain relief and had significantly lower postoperative opioid consumption during the first $24 \mathrm{~h}$ postoperatively, compared with those receiving opioid alone. The results of the current meta-analysis were consistent with those findings, and provided evidence to support the safety of dexmedetomidine administration for more than $24 \mathrm{~h}$. An updated meta-analysis by Peng et al. [45] also examined the safety of prolonged use of dexmedetomidine after surgery; our present findings are consistent with those of the updated analysis. However, previous meta-analyses included studies that used various opioids and were published before 2017. Although data regarding opioid equianalgesic conversion factors have been previously published, their pharmacokinetics and pharmacodynamics were not exactly same. In our meta-analysis, we solely included studies using sufentanil, which has a smaller volume of distribution, shorter elimination half-life, and more rapid recovery than either fentanyl or morphine [46]. Sufentanil exhibits a wider therapeutic index than other opioids for PCA [28], is the most potent available analgesic, and is the most commonly used for intravenous PCA. Six of 9 RCTs in our meta-analysis were published after 2017. When dexmedetomidine was added to PCA, previous meta-analysis [45] reported that the morphine-equivalent consumptions during the first 24 and $48 \mathrm{~h}$ after surgery decreased by $12.16 \mathrm{mg}$ and $10.15 \mathrm{mg}$, respectively. This suggested that dexmedetomidine may be ineffective during the first 24 to $48 \mathrm{~h}$ after surgery. In contrast, our results showed that when dexmedetomidine was added to PCA, sufentanil consumption during the first 24 and $48 \mathrm{~h}$ postoperatively decreased by $13.77 \mu \mathrm{g}$ and $20.81 \mu \mathrm{g}$, respectively. Our meta-analysis therefore indicated that the analgesic effect of dexmedetomidine continued throughout the first $48 \mathrm{~h}$ postoperatively.

There were several limitations in our meta-analysis. First, it included a small number of studies; however, we included all literature available. Second, all studies investigated Chinese adult patients, although they were reported in English. It remains unknown whether our findings are applicable to patients of other ethnicities. Third, surgery types and perioperative anesthesia protocols varied among studies, as did the doses of dexmedetomidine and sufentanil; thus, the included studies exhibited high heterogeneity. Fourth, the present study did not assess the dose-response effects for different types of surgeries. Additional RCTs are needed to identify the optimal doses of dexmedetomidine and sufentanil for different surgeries. Finally, publication biases and potential biases may influence our results.

\section{Conclusions}

Compared with sufentanil alone, dexmedetomidinesufentanil combination for postoperative intravenous PCA may achieve better analgesia and patient satisfaction, thereby reducing sufentanil consumption and sufentanil-related complications.

\begin{abstract}
Abbreviations
Cl: Confidence interval; DEX: Dexmedetomidine; GRADE: The grading of recommendations, assessment, development, and evaluation methodology; MD: Mean difference; NRS: Numerical rating scale; PCA: Patient-controlled analgesia; PONV: Postoperative nausea and vomiting; PRISMA: Preferred reporting items for systematic reviews and meta-analyses; RCT: Randomized controlled trial; RR: Risk ratio; SMD: Standardized mean difference; VAS: Visual analogue scale
\end{abstract}

\section{Acknowledgements}

Not Applicable.

Funding

No funding.

Availability of data and materials

All data generated or analyzed during this study are included in this published article.

\section{Authors' contributions \\ MF and WY designed and conceived the study, performed the statistical analysis, and drafted the manuscript. XC and TL participated in the interpretation of data, analysis, and drafting of the manuscript. CZ and LW participated in the study design and coordination, and helped to draft the manuscript. All authors read and approved the final manuscript.}

Ethics approval and consent to participate

Not applicable.

Consent for publication

Not applicable.

Competing interests

The authors declare that they have no competing interests.

\section{Publisher's Note}

Springer Nature remains neutral with regard to jurisdictional claims in published maps and institutional affiliations.

Received: 9 September 2018 Accepted: 10 May 2019

Published online: 18 May 2019

References

1. Pogatzki-Zahn EM, Segelcke D, Schug SA. Postoperative pain-from mechanisms to treatment. Pain Rep. 2017;2:e588.

2. Kehlet H, Dahl JB. Anaesthesia, surgery, and challenges in postoperative recovery. Lancet. 2003;362:1921-8.

3. Costa JR, Coleman R. Post-operative pain management using patientcontrolled analgesia. Clin Podiatr Med Surg. 2008;25:465-75.

4. Dahan A, Aarts L, Smith TW. Incidence, reversal, and prevention of opioidinduced respiratory depression. Anesthesiology. 2010;112:226-38.

5. Imam MZ, Kuo A, Ghassabian S, Smith MT. Progress in understanding mechanisms of opioid-induced gastrointestinal adverse effects and respiratory depression. Neuropharmacology. 2017;131:238-55. 
6. American Society of Anesthesiologists Task Force on Acute Pain Management. Practice guidelines for acute pain management in the perioperative setting: an updated report by the American Society of Anesthesiologists Task Force on Acute Pain Management. Anesthesiology. 2012;116:248-73.

7. Gertler R, Brown HC, Mitchell DH, Silvius EN. Dexmedetomidine a novel sedative analgesic agent. Proc (Bayl Univ Med Cent). 2001;14:13-21.

8. Kamibayashi T, Maze M. Clinical uses of alpha2 -adrenergic agonists. Anesthesiology. 2000;93:1345-9.

9. Paris A, Tonner PH. Dexmedetomidine in anaesthesia. Curr Opin Anaesthesiol. 2005;18:412-8.

10. Ebert TJ, Hall JE, Barney JA, Uhrich TD, Colinco MD. The effects of increasing plasma concentrations of Dexmedetomidine in humans. Anesthesiology. 2000;93:382-94.

11. Zhou C, Zhu Y, Liu Z, Ruan L. Effect of dexmedetomidine on postoperative cognitive dysfunction in elderly patients after general anaesthesia: a metaanalysis. J Int Med Res. 2016:44:1182-90.

12. Wu XH, Cui F, Zhang C, Meng ZT, Wang DX, Ma J, et al. Low-dose Dexmedetomidine improves sleep quality pattern in elderly patients after noncardiac surgery in the intensive care unit: a pilot randomized controlled trial. Anesthesiology. 2016;125:979-91.

13. Peng K, Liu HY, Wu SR, Cheng H, Ji FH. Effects of combining Dexmedetomidine and opioids for postoperative intravenous patientcontrolled analgesia: a systematic review and meta-analysis. Clin J Pain. 2015;31:1097-104

14. Bailey PL, Streisand JB, East KA, East TD, Isern S, Hansen TW, et al. Differences in magnitude and duration of opioid-induced respiratory depression and analgesia with fentanyl and Sufentanil. Anesth Analg. 1990;70:8-15.

15. Higgins JPT, Green S. Cochrane Handbook for Systematic Reviews of Interventions Version 5.1.0. The Cochrane Collaboration; 2011. Available from https://handbook-5-1.cochrane.org/.

16. Liberati A, Altman DG, Tetzlaff J, Mulrow C, Gotzsche PC, loannidis JP, et al. The PRISMA statement for reporting systematic reviews and metaanalyses of studies that evaluate healthcare interventions: explanation and elaboration. BMJ. 2009;339:b2700.

17. Higgins JP, Altman DG, Gotzsche PC, Juni P, Moher D, Oxman AD, et al The Cochrane Collaboration's tool for assessing risk of bias in randomised trials. BMJ. 2011;343:d5928.

18. Balshem $H$, Helfand M, Schunemann HJ, Oxman AD, Kunz R, Brozek J, et al. GRADE guidelines: 3. Rating the quality of evidence. J Clin Epidemiol. 2011; 64:401-6.

19. Jessen Lundorf L, Korvenius Nedergaard H, Moller AM. Perioperative dexmedetomidine for acute pain after abdominal surgery in adults. Cochrane Database Syst Rev. 2016;2:CD010358.

20. Wan X, Wang W, Liu J, Tong T. Estimating the sample mean and standard deviation from the sample size, median, range and/or interquartile range. BMC Med Res Methodol. 2014:14:135.

21. Sun S, Wang J, Bao N, Chen Y, Wang J. Comparison of dexmedetomidine and fentanyl as local anesthetic adjuvants in spinal anesthesia: a systematic review and meta-analysis of randomized controlled trials. Drug Des Devel Ther. 2017:11:3413-24.

22. Hu J, Zhang C, Yan J, Wang R, Wang Y, Xu M. Sufentanil and bupivacaine combination versus bupivacaine alone for spinal anesthesia during cesarean delivery: a meta-analysis of randomized trials. PLoS One. 2016;11:e0152605.

23. Cai X, Zhang $P$, Lu S, Zhang Z, Yu A, Liu D, et al. Effects of Intraoperative Dexmedetomidine on Postoperative Pain in Highly Nicotine-Dependent Patients After Thoracic Surgery: A Prospective, Randomized, Controlled Trial. Medicine (Baltimore). 2016;95:e3814

24. Wang K, Li C, Shi J, Wei H. Effects of patient-controlled intravenous analgesia with dexmedetomidine and sufentanil on postoperative cognition in elderly patients after spine surgery. Zhonghua Yi Xue Za Zhi. 2015;95:2437-41.

25. Chen Z, Tang R, Zhang R, Jiang Y, Liu Y. Effects of dexmedetomidine administered for postoperative analgesia on sleep quality in patients undergoing abdominal hysterectomy. J Clin Anesth. 2017:36:118-22.

26. Gao Y, Deng X, Yuan H, Leng Y, Zhang T, Xu X, et al. Patient-controlled intravenous analgesia with combination of Dexmedetomidine and Sufentanil on patients after abdominal operation: a prospective, randomized, controlled, blinded, multicenter clinical study. Clin J Pain. 2018;34:155-61.

27. Nie Y, Liu Y, Luo Q, Huang S. Effect of dexmedetomidine combined with sufentanil for post-caesarean section intravenous analgesia: a randomised, placebo-controlled study. Eur J Anaesthesiol. 2014;31:197-203.
28. Dong CS, Zhang J, Lu Q, Sun P, Yu JM, Wu C, et al. Effect of Dexmedetomidine combined with sufentanil for post- thoracotomy intravenous analgesia: a randomized, controlled clinical study. BMC Anesthesiol. 2017;17:33.

29. Qin M, Chen K, Liu T, Shen X. Dexmedetomidine in combination with sufentanil for postoperative analgesia after partial laryngectomy. BMC Anesthesiol. 2017;17:66.

30. Lu J, Chen G, Zhou H, Zhou Q, Zhu Z, Wu C. Effect of parecoxib sodium pretreatment combined with dexmedetomidine on early postoperative cognitive dysfunction in elderly patients after shoulder arthroscopy: a randomized double blinded controlled trial. J Clin Anesth. 2017:41:30-4.

31. Ren C, Zhang X, Liu Z, Li C, Zhang Z, Qi F. Effect of Intraoperative and Postoperative Infusion of Dexmedetomidine on the Quality of Postoperative Analgesia in Highly Nicotine-Dependent Patients After Thoracic Surgery: a CONSORT-Prospective, Randomized, Controlled Trial. Medicine (Baltimore). 2015;94:e1329.

32. Ren C, Chi M, Zhang Y, Zhang Z, Qi F, Liu Z. Dexmedetomidine in Postoperative Analgesia in Patients Undergoing Hysterectomy: a CONSORT-Prospective, Randomized, Controlled Trial. Medicine (Baltimore). 2015:94:e1348.

33. Xin J, Zhang Y, Zhou L, Liu F, Zhou X, Liu B, et al. Effect of dexmedetomidine infusion for intravenous patientcontrolled analgesia on the quality of recovery after laparotomy surgery. Oncotarget. 2017;8: 100371-83.

34. Hadi MA, Kamaruljan HS, Saedah A, Abdullah NM. A comparative study of intravenous patient-controlled analgesia morphine and tramadol in patients undergoing major operation. Med J Malaysia. 2006;61:570-6.

35. Kim NY, Kwon TD, Bai SJ, Noh SH, Hong JH, Lee $H$, et al. Effects of dexmedetomidine in combination with fentanyl-based intravenous patient-controlled analgesia on pain attenuation after open gastrectomy in comparison with conventional thoracic epidural and fentanyl-based intravenous patient-controlled analgesia. Int J Med Sci. 2017;14:951-60.

36. Sjovall S, Kokki M, Kokki H. Laparoscopic surgery: a narrative review of pharmacotherapy in pain management. Drugs. 2015;75:1867-89.

37. Hankin CS, Schein J, Clark JA, Panchal S. Adverse events involving intravenous patient-controlled analgesia. Am J Health Syst Pharm. 2007; 64:1492-9.

38. Choi JB, Shim YH, Lee YW, Lee JS, Choi JR, Chang CH. Incidence and risk factors of postoperative nausea and vomiting in patients with fentanyl-based intravenous patient-controlled analgesia and single antiemetic prophylaxis. Yonsei Med J. 2014;55:1430-5.

39. Grosu I, Lavand'homme P. Use of dexmedetomidine for pain control. F1000 Med Rep. 2010;2:90.

40. Choi EK, Seo Y, Lim DG, Park S. Postoperative nausea and vomiting after thyroidectomy: a comparison between dexmedetomidine and remifentanil as part of balanced anesthesia. Korean J Anesthesiol. 2017: 70:299-304

41. Carollo DS, Nossaman BD, Ramadhyani U. Dexmedetomidine: a review of clinical applications. Curr Opin Anaesthesiol. 2008;21:457-61.

42. Frolich MA, Arabshahi A, Katholi C, Prasain J, Barnes S. Hemodynamic characteristics of midazolam, propofol, and dexmedetomidine in healthy volunteers. J Clin Anesth. 2011;23:218-23.

43. Maze M, Virtanen R, Daunt D, Banks SJ, Stover EP, Feldman D. Effects of dexmedetomidine, a novel imidazole sedative-anesthetic agent, on adrenal steroidogenesis: in vivo and in vitro studies. Anesth Analg. 1991;72:204-8.

44. Enomoto $Y$, Kudo $T$, Saito $T$, Hori $T$, Kaneko $M$, Matsui $A$, et al. Prolonged use of dexmedetomidine in an infant with respiratory failure following living donor liver transplantation. Paediatr Anaesth. 2006:16: 1285-8.

45. Peng $K$, Zhang J, Meng XW, Liu HY, Ji FH. Optimization of postoperative intravenous patient-controlled analgesia with opioid Dexmedetomidine combinations: an updated meta-analysis with trial sequential analysis of randomized controlled trials. Pain Physician. 2017; 20:569-96.

46. Bovill JG, Sebel PS, Blackburn CL, Oei-Lim V, Heykants JJ. The pharmacokinetics of sufentanil in surgical patients. Anesthesiology. 1984;61: 502-6. 